\title{
Propositura de Construto para Utilização Prática de Red Flags em Auditoria
}

\section{Building Flags for Use of Red Flags in Auditing}

Edenis Cesar de Oliveira1 ${ }^{1}$, Nilton Cezar Carraro², Leandro de Caires Siqueira ${ }^{3}$, Otávio Augusto Izidio de Almeida ${ }^{4}$, Yohans de Oliveira Esteves ${ }^{5}$

\section{RESUMO}

A auditoria contábil está sofrendo alterações para acompanhar as necessidades impostas pelas evoluções do mercado. Logo, como um estudo descritivo e apoiado na teoria de Albrecht e Romney (1986), sobre a utilização de red flags em bases financeiras e operacionais como forma de detecção de fraudes, este trabalho teve como objetivo a construção de um modelo prático, originando um novo softwareque, apoiado no teste de Cronbach, validou a consistência interna dos pares de red flags apresentados de acordo com seu alcance, para posteriormente, com base no método de Bardin (1991), identificar e correlacionar as variáveis financeiras e operacionais. A aplicação do modelo/software se deu em demonstrações contábeis e relatórios das cinco maiores empresas públicas brasileiras, escolhidas por conveniência, face aos processos de corrupção que estão ligadas. Como resultado obteve-se o cruzamento dos red flags apresentados na Figura 1, que representam indícios de erros ou fraudes nas empresas analisadas, sinalizando para o auditor, que estes pontos merecem atenção, segundo o arcabouço teórico e legal consultado. Esta foi a principal contribuição do modelo e do software, que deverá ser utilizado como forma de percepção complementar aos métodos existentes, ampliando a possibilidade de análise devido ao potencial de processamento de informações.

Palavras-chave: Financial Basis. Non-financial Basis. Red Flags Fraudes. Auditoria.

\section{ABSTRACT}

The accounting audit is undergoing changes to keep up with the needs imposed by market developments. Therefore, as a descriptive study supported by the theory of Albrecht e Romney (1986), on the use of red flags on financial and operational bases as a form of fraud detection, this work had as objective the construction of a practical model, originating a new software, which supported the Cronbach test, validated the internal consistency of the pairs of red flags presented according to their scope, for later, based on the method of Bardin (1991), identify and correlate financial and operational variables. The application of the model / software took place in the financial statements and reports of the five largest Brazilian public companies, chosen for convenience, in view of the corruption processes that are linked. As a result, we obtained the crossing of the red flags shown Figure 1, which represent signs of errors or fraud in the analyzed companies, signaling to the audit, that these points deserve attention, according to the theoretical and legal framework consulted. This was the main contribution of the model and software, which should be used as a way of understanding complementary to existing methods, expanding the possibility of analysis due to the potential of information processing.

Keywords: Financial Basis. Non-financial Basis. Red Flags. Fraud. Auditing. 


\section{INTRODUCÁO}

Ao longo das últimas décadas a auditoria contábil sofreu várias mudanças visando proteger os interesses de diversos players no cenário econômico, que depositam no trabalho dos auditores independentes a confiança necessária para a validação dos atos praticados pelos gestores das auditadas, devendo estar em acordo com a legislação.

Um exemplo disso é a lei Sarbanes-Oxley, também conhecida como SOx, proposta pelo senador Paul Sarbanes e pelo deputado Michael Oxley, criada nos Estados Unidos em 2002, em decorrência de casos de fraude e escândalos de corrupção contábil envolvendo grandes empresas como a Enron, Arthur Andersen, WorldCom, Xerox, entre outras. O objetivo principal dessa lei era evitar a fuga dos investidores, causada pela insegurança e perda de confiança, em relação às escriturações contábeis e aos princípios de governança, sendo aplicável às empresas americanas ou estrangeiras que tenham ações registradas na Securities and Exchange Commission (SEC), o equivalente americano da Comissão de Valores Mobiliários (CVM) no Brasil.

No Brasil, de acordo com a pesquisa de Ricardino e Carvalho (2004), a auditoria independente surgiu em meados de 1910, na cidade do Rio de Janeiro, onde se instalou a primeira empresa de Auditoria Independente. Em 1950 foi publicado o livro "Curso de Auditoria", que passou a nortear a atuação dos auditores, referindo-se aos aspectos legais. Em 1965 foi instituída a função do auditor independente como diploma no Brasil, surgindo o Instituto dos Contadores Públicos do Brasil (ICPB) e o Instituto Brasileiro de Auditores Independentes (IBAI), que posteriormente foram unificados dando origem ao Instituto dos Auditores Independentes do Brasil (IBRACON), com missão de preservar a confiança da sociedade na atividade de auditoria independente.

Portanto, o grande marco na legislação brasileira relacionado ao mercado de capitais concentra-se nas décadas de 1960 e 1970. É dessa época a resolução № 88/68, do Banco Central do Brasil (BCB), que disciplinou o registro de empresas no mercado de capitais, impondo a obrigatoriedade da auditoria independente (IBRACON, 2016). Pouco tempo depois, em 1976, foi necessária a criação da lei 6.404, que regulamentou a legislação sobre as sociedades por ações. A partir de meados da década de 1980, com a abertura de mercados internacionais, evento denominado de globalização, a auditoria contábil passou a ter um valor ainda maior para a proteção das partes interessadas (stakeholders).

Apesar disso, no Brasil, cada vez mais se tem notícias de escândalos com fraudes executadas por más administrações, em especial de empresas públicas, onde a auditoria 
torna-se uma ferramenta de grande importância, pois possibilita evidenciar as irregularidades ocorridas, ensejando novos procedimentos com o objetivo de investigar fraudes e corrupções. A Petrobrás é o principal exemplo, com a operação investigativa denominada Lava Jato.

Logo, torna-se evidente que uma ocorrência de fraude interna está ligada a um ambiente propício ao seu surgimento, que pode ser identificado em tempo quando utilizado pelas auditorias por meio dos chamados red flags (sinais de alerta). Conforme evidenciado nas pesquisas de Albrecht e Romney (1986), Eining et al. (1997), Bell e Carcacello (2000) e Wells (2005), os red flags são termômetros para detecção e prevenção de fraudes internas.

Visando contribuir com a auditoria independente, este estudo apoiado nas teorias apresentadas na próxima seção sobre a utilização dos red flags em bases financeiras e operacionais, tem como objetivo a construção de um modelo prático para utilização dos red flags em auditoria, materializado através de um software, cuja aplicabilidade será testada nas cinco maiores empresas públicas brasileiras que estão envolvidas em processos de corrupção. Para tanto, foram utilizadas informações extraídas dos relatórios da Controladoria Geral da União (CGU) e também das próprias demonstrações contábeis e relatórios emitidos por essas empresas.

\section{FUNDAMENTAÇÃO TEÓRICA}

A maioria das pesquisas realizadas por acadêmicos e práticos em contabilidade normalmente abordam as fraudes subdividindo-as em grupos ou tipos (SOUZA, 2012). Para ACFE - Association of Certified Fraud Examiners (2016), as fraudes estão divididas em três grupos, sendo o primeiro deles a corrupção que envolve um esquema ardiloso, onde a principal bandeira é a influência sobre agentes econômicos externos e internos, o segundo é a apropriação indevida de ativos que também está relacionada à influência, porém com características diferentes, muitas vezes não envolvendo participação externa, e, o terceiro são as demonstrações financeiras fraudulentas que envolvem toda sorte de manipulação de dados com o objetivo de esconder ato fraudulento de gestão.

Reinstein e McMillan (2004), afirmaram que os red flags são sinais de perigo que visam alertar os auditores independentes sobre a possível ocorrência de uma fraude, uma vez que a auditoria é geralmente realizada por procedimentos aplicados em amostras, não contemplando a totalidade das transações ocorridas na empresa. Desta maneira, para que 
este processo seja eficaz, se faz necessário um entendimento do ambiente organizacional, onde o auditor independente deverá identificar possíveis indícios de fraude (ALBRECHT, 2003).

Para os autores já citados na introdução, a existência de uma pressão excessiva sobre os executivos da entidade para que atinjam as metas estipuladas pelo conselho de administração, torna-se um ambiente propício para fraude. Portanto, conhecer os diversos red flags relacionados às fraudes contábeis, tende a propiciar maior compreensão acerca do ambiente fraudulento. Murcia et al. (2008) afirmaram que detectar a presença de uma fraude através da análise das demonstrações contábeis pode ser extremamente difícil.

Em alguns casos, fraudadores desviam do sistema contábil (go around the accounting system) e produzem as informações desejadas por eles. Portanto, faz-se necessário entender como os red flags podem atuar em financial basis (financeiro) e non-financial basis (operacional).

\subsection{A utilização de red flags em financial basis}

As empresas de capital aberto devem publicar as demonstrações dos seus resultados financeiros via Comissão de Valores Mobiliários (CVM), devendo seguir suas normas, regulamentos, prazos, sendo obrigadas a contratarem empresas especializadas em serviços de auditoria independente para avaliarem a veracidade, fidedignidade e relevância das informações constantes nas suas demonstrações contábeis conforme o Pronunciamento Conceitual Básico (R1) do Comitê de Pronunciamentos Contábeis (CPC), Correlação às Normas Internacionais de Contabilidade - The Conceptual Framework for Financial Reporting (IASB - BV, 2011 Blue Book).

De modo geral, as demonstrações contábeis devem ser elaboradas de forma imparcial, buscando retratar fidedignamente a situação econômica, financeira e patrimonial da empresa, a fim de gerar informações úteis e relevantes para o processo de decisão de seus respectivos usuários, dentre eles investidores, credores, fisco, órgãos reguladores, consumidores, competidores e sindicatos (STICKNEY e WEIL, 2000).

Complementando a citação anterior, de acordo com o pronunciamento $\mathrm{n}^{\circ}$ 26/2011 do Comitê de Pronunciamentos Contábeis (CPC), as demonstrações contábeis têm por objetivo proporcionar informação ao usuário da contabilidade acerca da posição patrimonial, financeira e dos fluxos de caixa da entidade, devendo-se objetivar a 
apresentação dos resultados financeiros da atuação da administração. Para Murcia e Borba (2007), a detecção de fraudes nesses resultados financeiros, mesmo perante a fiscalização de órgãos reguladores, é muito dificultosa de se fazer, pois o processo de geração da informação contábil é arbitrário e sujeito ao julgamento humano.

Neste cenário, segundo Kranacher et al. (2010), os red flags surgem como uma espécie de fios soltos, anomalias, fatos, que sugerem que algo pode não estar certo, sendo usado como sinônimo de sintomas de fraude, considerada ferramenta fundamental a fim de alertar e prevenir as possíveis ocorrências que podem não ser evidenciadas através das demonstrações contábeis.

O resultado da pesquisa bibliográfica apontou para vários red flags utilizados para percepção de erros e fraudes em demonstrações contábeis. Dentre eles, segundo o objetivo deste trabalho, destacam-se os apontados no Quadro 1. É preciso recordar que os mesmos serão utilizados neste trabalho apenas em empresas públicas, logo, tanto a quantidade como o alcance ocorreram nesse sentido.

Quadro 1. Red flags em financial basis

\begin{tabular}{ccl}
\hline Autor & Ano & \multicolumn{1}{c}{ Alcance dos reds flags } \\
\hline CFC & 1999 & $\begin{array}{l}\text { O capital de giro da entidade não é considerado suficiente para } \\
\text { financiar as suas operações. }\end{array}$ \\
\hline CFC & 1999 & $\begin{array}{l}\text { A entidade muda sua empresa de auditoria constantemente. } \\
\text { Wells }\end{array}$ \\
\hline Wells & 2005 & $\begin{array}{l}\text { Apontou o índice de liquidez baixo (Ativo circulante dividido pelo } \\
\text { passivo circulante) como indicativo de falta de estabilidade } \\
\text { financeira da entidade. }\end{array}$ \\
\hline Wells & 2005 & $\begin{array}{l}\text { O nível de competitividade é alto ou existe uma saturação do } \\
\text { mercado que vem gerando variação do lucro. }\end{array}$ \\
\hline Esteves & 2012 & $\begin{array}{l}\text { Repetições significativas de transações com partes relacionadas } \\
\text { (controladora - subsidiária), ou transações com companhias não } \\
\text { auditadas, ou auditadas por outras firmas que não a mesma. }\end{array}$ \\
\hline
\end{tabular}

Fonte: Adaptado pelos autores.

Cressey (1954) elaborou um modelo de triângulo da fraude que agrupa esses destacados no Quadro 1 dentre uma lista mais ampla, dividindo-a em três partes: oportunidade, pressão/incentivos e racionalização/atitudes.

Moura e Silva (2004) afirmaram ser necessário aumentar a percepção da detecção de fraudes para que se diminua o risco de sua ocorrência da seguinte forma: vigilância, denúncias anônimas, auditorias/inspeções de surpresa, responsabilização e acusação, 
ações concretas internas da empresa e recompensa por ajuda, classificando-os em documentais (suportadas em documentos, contratos e outros), pessoais (comportamento das pessoas), processuais (análise de como foram efetuados gastos), conceituais (observação do auditor).

Wuerges (2010) defendeu a utilização de todos os red flags apontados no Quadro 1 para que haja o efetivo alcance referente a todos esses clusters, pois poderá melhorar a existência de diversas variáveis envolvidas nas fraudes.

Logo, a pertinência dos red flags apontados no Quadro 1, serão demonstrados com maior propriedade na terceira seção, que apresenta a metodologia e lógica utilizadas para a construção do modelo prático materializado através de um software. Para o alcance do objetivo exposto, faz-se necessário apresentar a segunda etapa da fundamentação teórica, que aborda a escolha e pertinência dos red flags em bases operacionais.

\subsection{A utilização de red flags em non-financial basis}

A ausência de controles e procedimentos internos, um mercado pouco regulado e pessoas desprovidas de boa índole ou com conduta questionável, podem ser caracterizados como início para atuação de atividades de caráter doloso contra a organização (MOURA, 2007).

Dessa maneira, a entidade deverá buscar um controle interno forte e consistente na prevenção de fraudes de pequeno ou grande porte, pois a grande maioria das operações é feitas por pessoas, que podem não estar agindo de forma imparcial ou íntegra, sofrendo algum dos sintomas do "triângulo da fraude" que são o incentivo a pressão, a oportunidade e a atitude/racionalização.

Fortalecendo essa busca, Kranacher et al. (2010), afirmaram que os red flags também são utilizados para prevenção de fraudes internas em operações do cotidiano, onde normas e medidas internas da própria entidade podem falhar na execução do compliance, controle e auditoria interna, complementando as lacunas existentes entre estes três elos de asseguração.

Com um sistema interno eficiente, os red flags tem caráter informativo para indicar os principais problemas operacionais numa empresa, ajudando os auditores internos em seu trabalho. Sá e Hoog (2012) citaram como vias para tanto a conferência de documentos; títulos de crédito e cheques; balanços; diários e razões; demonstrações contábeis, entre 
outros. Nesse sentido, a automatização proporcionada por um software poderá ser um avanço, aumentando o volume de documentos analisados e auditados via red flags.

Em uma relação de causa e efeito, uma decisão operacional errada ou fraudulenta causará um impacto negativo nas finanças das empresas. Segundo o MPF (2017), isso tem sido evidenciado na operação Lava Jato, principalmente nos casos em que empreiteiras eram contratadas para a realização de obras que muitas vezes não precisariam existir ou até mesmo em aquisições para operações desnecessárias.

O Quadro 2 apresenta uma síntese no tocante a apresentação de red flags mais frequentes que podem ocorrer dentro de um ambiente fraudulento envolvendo as operações. A exemplo do Quadro 1, os mesmos foram identificados e selecionados de acordo com o objetivo da pesquisa e a amostra utilizada.

Quadro 2. Red flags em non-financial basis

\begin{tabular}{|c|c|c|}
\hline Autor & Ano & Alcance dos red flags \\
\hline Albrecht e Romney & 1986 & Administração desonesta e não ética. \\
\hline CFC & 1999 & A reputação da administração é duvidosa. \\
\hline CFC & 1999 & $\begin{array}{l}\text { A entidade está participando de transações } \\
\text { consideradas relevantes. }\end{array}$ \\
\hline Bell e Carcacello & 2000 & $\begin{array}{l}\text { Entidade está enfrentando problemas legais/ } \\
\text { judiciais. }\end{array}$ \\
\hline Wells & 2005 & Crescimento anormal nos estoques da entidade. \\
\hline Esteves & 2012 & $\begin{array}{l}\text { A entidade passa por um momento de rápida } \\
\text { expansão-aquisição. }\end{array}$ \\
\hline Rustiarini e Novitasari & 2014 & $\begin{array}{l}\text { A educação, a experiência e o treinamento de fraude } \\
\text { influenciam a percepção do auditor }\end{array}$ \\
\hline Purwanti e Astika & 2017 & $\begin{array}{l}\text { Os sinais de alerta profissionais podem dos } \\
\text { auditores têm um efeito positivo em sua capacidade } \\
\text { de detectar fraudes, ao passo que a carga de } \\
\text { trabalho tem um efeito negativo }\end{array}$ \\
\hline
\end{tabular}

Fonte: Elaborado pelos autores

Os red flags de maneira geral são utilizados como um todo, sem a separação representada pelos Quadros 1 e 2. Entretanto, neste trabalho, por conveniência, resolveuse separá-los, justamente para criar condições de causa e efeito, que foram utilizadas como variáveis e que serão demonstradas na próxima seção.

\section{MATERIAIS E MÉTODOS}

O presente estudo é classificado como de natureza descritiva o qual tem como objetivo descrever as características de determinada população ou fenômeno, com uma abordagem do tema qualitativa, que na visão de Raupp e Beuren (2006), consiste em conhecer as razões que qualificam o objeto do estudo). 
Para tanto, foi realizada inicialmente um levantamento bibliográfico sobre os red flags que resultou na fundamentação teórica apresentada na seção anterior, possibilitando a elaboração da construção de um modelo de cruzamento de sinalizadores com base financeira e operacional, originando o Quadro 3.

A coluna da esquerda representa os red flags evidenciados no Quadro 1, enquanto a da direita representa o Quadro 2. O cruzamento entre ambas dá origem à relação entre causa e efeito, gerando variáveis, pois além da percepção desses pesquisadores, também foi utilizado o teste do Alfa de Cronbach (CRONBACH, 1951; 2004) e princípios do método de análise de conteúdo proposto por Bardin (1991) para a validação e construção do proposto.

O teste de Cronbach foi desenvolvido com o intuito de garantir a fidedignidade ou consistência interna de um teste, envolvendo variáveis aleatórias, tendo sua interpretação como a de um coeficiente de correlação ao quadrado (APPOLINÁRIO, 2011), onde para cada red flag na coluna da esquerda descrita como financial basis, tem o mesmo poder de representação na coluna da direita descrita como non-financial basis.

Quadro 3. Cruzamento de red flags entre bases financeiras e operacionais

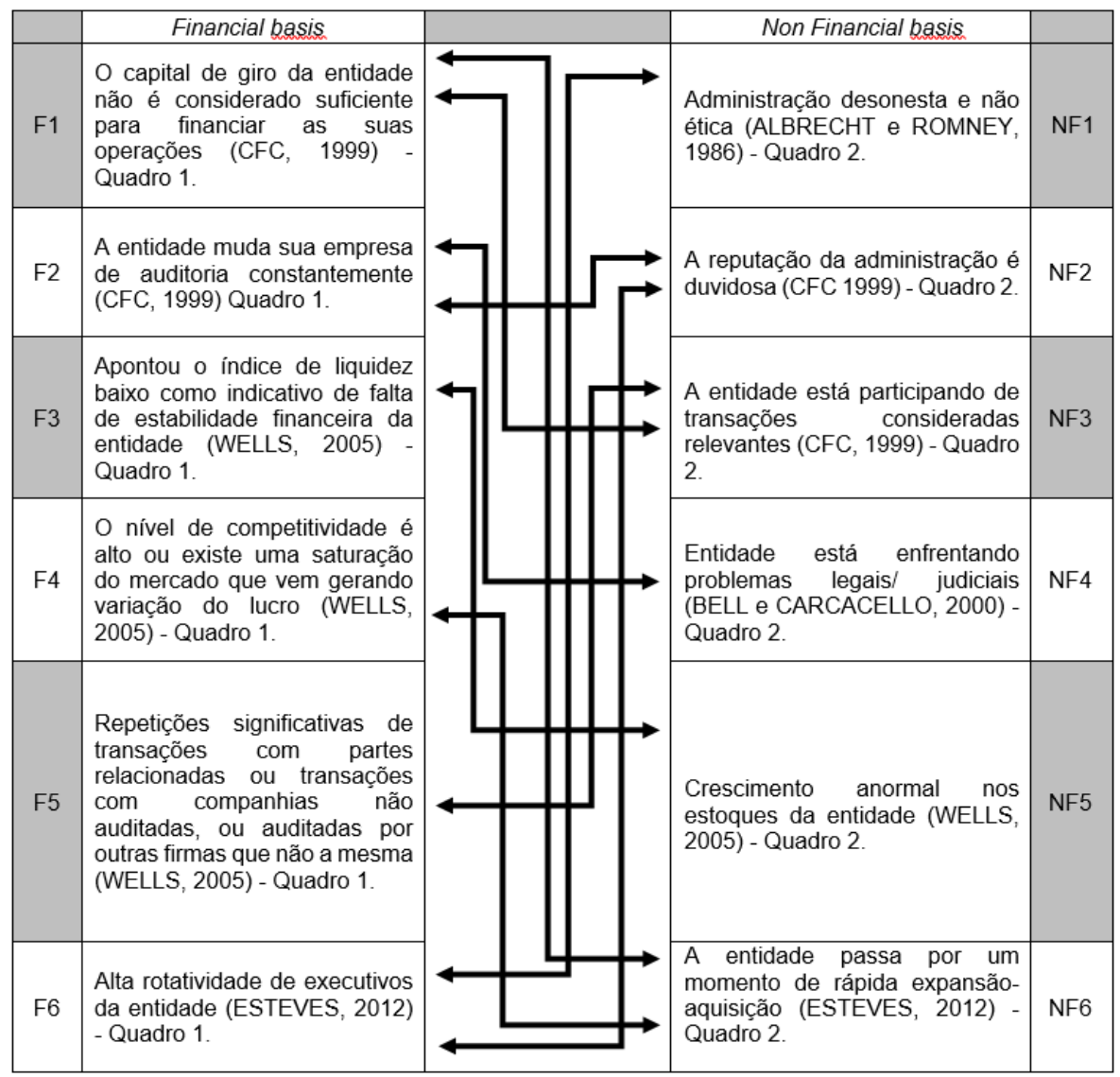

Fonte: Elaborado pelos autores 
Este teste foi aplicado na fase de revisão de literatura, onde muitos red flags foram identificados, entretanto, por meio de um questionário inicialmente respondido pelos pesquisadores e, posteriormente, por um grupo maior de colaboradores acadêmicos, com objetivo especifico de análise das empresas em questão, testando a aderência no cruzamento, chegou-se a um resultado próximo a $80 \%$, caracterizando então o pressuposto inicial do objetivo dessa pesquisa, que é o construto demonstrado no Quadro 3.

Uma vez elaborado o filtro e determinado o construto em seis pares, para aplicá-lo devido ao grande número de informações a serem tratadas, foi construído um software que está em fase de registro. Não obstante, a ferramenta conta com a aplicabilidade de princípios do método de Bardin (1991), que consiste em procedimentos sistemáticos e objetivos de descrição do conteúdo de mensagens e indicadores quantitativos, permitindo identificar as variáveis contidas nestes.

Para testar a efetividade do construto proposto no Quadro 3, foram selecionadas cinco das principais empresas públicas brasileiras, sendo elas o Banco do Brasil (BB), Banco Nacional do Desenvolvimento (BNDES), Caixa Econômica Federal (CEF), Empresa Brasileira de Correios e Telegrafo (CORREIOS) e a Petróleo Brasileiro S.A. (PETROBRAS). A escolha se deu por conveniência em função dos relatos constantes de fraude e corrupção envolvendo estas empresas, noticiados quase que diariamente na grande imprensa.

Para aplicação dos sinalizadores foram utilizados relatórios referentes aos anos de 2014 e 2015, obtidos juntos a CGU e junto aos relatórios das empresas mencionadas, cujos resultados serão discutidos na próxima seção.

\section{RESULTADOS E DISCUSSĀO}

A busca dos dados para aplicação do construto apresentado no Quadro 3 se deu nos pareces das auditorias e nas recomendações de ajustes, notas explicativas das demonstrações contábeis e falhas/distorções que ocorriam dentro das mesmas, conforme detalhamento do endereço eletrônico e página dos relatórios, constantes no apêndice. Essas informações foram importadas para o software mencionado na seção anterior, onde, através do alcance dos red flags, foi possível chegar a síntese apresentada pela Figura 1, demonstrando o cruzamento para cada empresa analisada, evidenciando a propensão erros ou fraudes e o seu tipo de acordo com causa e consequência, portanto, se proveniente de operações financeiras ou operacionais. 


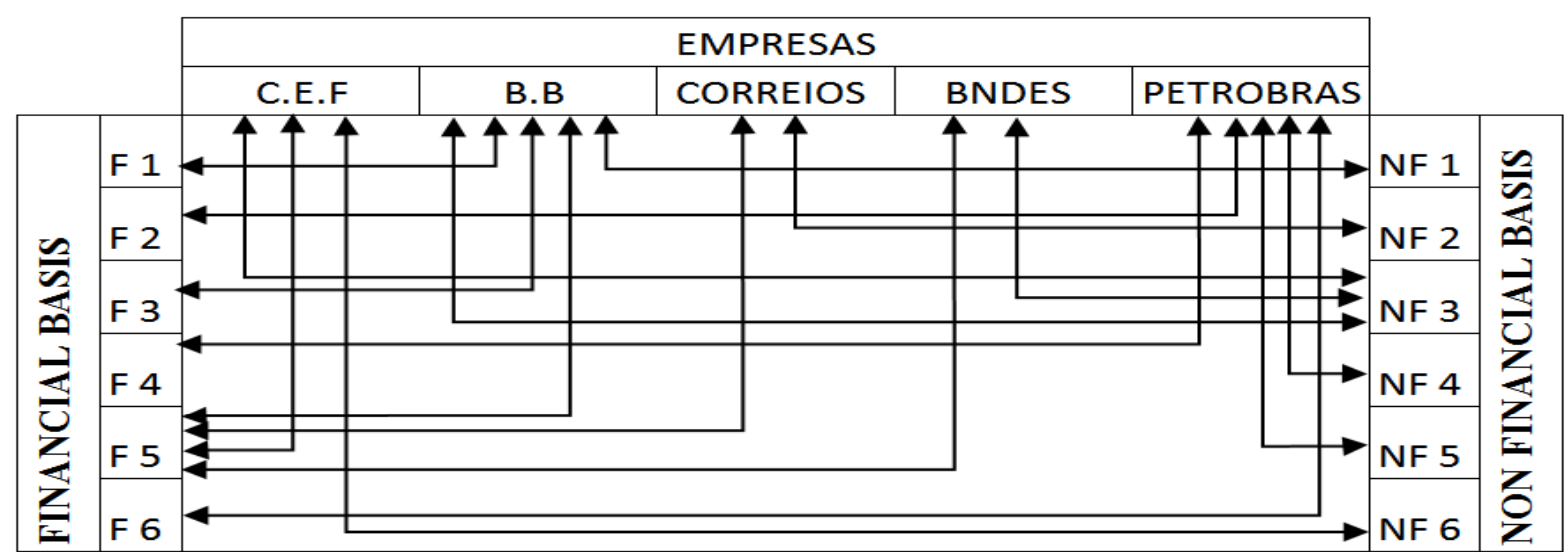

Figura 1. Cruzamento de red flags das empresas pesquisadas nos anos de 2014 e 2015.

Fonte: Elaborado pelos autores com base nos sites identificados no apêndice

Analisando os resultados, a CEF está propensa ao cruzamento identificado entre os red flags F5 e NF3 e NF6, enquanto que o BNDES está sujeito ao cruzamento entre F5 e NF3. Para Wells (2005), CFC (1999) e Esteves (2012) repetições significativas de transações com partes relacionadas (controladora - subsidiária), ou transações com companhias não auditadas, ou auditadas por outras firmas que não a mesma, guarda relação com transações relevantes e rápida expansão, conforme apontado nos relatórios da CGU, identificados no apêndice. Esses red flags indicam aos stakeholders especial atenção às decisões que a empresa toma nesta área, podendo gerar conflitos de interesse e até mesmo erros ou fraudes. É importante salientar que o software conseguiu identificar as negociações relevantes (NF3) como causa e os negócios com partes relacionadas (F5) como consequência.

Para se chegar a estas considerações em relação a CEF, foram imputados no software os relatórios completos da CGU e para o BNDES, as demonstrações financeiras, as notas explicativas e relatórios da administração. À medida que o programa processava cada linha de relatório, os cruzamentos ocorriam, apresentando em tela a origem da informação conforme identificação no apêndice, resultando nos apontamentos apresentados na Figura 1.

Para a PETROBRAS, os red flags F2, F4, F6, NF4 e NF5, respectivamente financeiros e não financeiros, que, para os autores mencionados na fundamentação teórica envolvidos pelos Quadros 1 e 2, aconselham os investidores que tenham certa cautela antes de investir, pois são red flags que indicam que algo de muito grave está acontecendo nessa empresa, como por exemplo problemas de ordem legal/judicial, alta rotatividade dos 
executivos, nível de competitividade alto ou saturação do mercado, variação negativa do lucro.

A relação entre causa e efeito aponta para situações não cotidianas, principalmente no tocante ao crescimento anormal do estoque, que, portanto, deverá ser motivo de extrema observação pelo auditor. Mesmo que não haja qualquer evidência de corrupção em uma auditada, ainda assim, esse cruzamento permite ao auditor checar se as políticas de mercado da empresa estão de acordo com as normas de asseguração estabelecidas pelo seu conselho.

Ainda sobre a PETROBRAS, essas notações são mais do que públicas, principalmente pelos escândalos revelados pela operação Lava Jato. Entretanto, 0 construto e o cruzamento desses red flags, mesmo sendo evidente pela publicidade do caso, foi notificado pelo software em cruzamentos específicos, conforme apontado no apêndice, denotando a sua prática. A empresa CORREIOS tem como análise os mesmos relatos da PETROBRÁS, uma vez que os red flags financeiros e não financeiros apurados são o F5 e NF2. A subjetividade neste caso pode ser grande, então poderá se estabelecer um filtro maior, ou seja, a ampliação de red flags nessa linha de investigação, ou então, aumentar o contingente para uma revisão mais ampla nos contratos estabelecidos no período.

$\mathrm{Na}$ análise feita no relatório da administração e no relatório de auditoria da CGU, foram detectados para o Banco do Brasil os red flags F1; F3; F5 e NF1; NF3, no qual para Wells (2005), fica evidente que o número de transações significativamente repetidas com empresas não auditadas e o baixo índice de liquidez da corporação, sinaliza uma possível falta de estabilidade financeira da mesma, e segundo o CFC (1999) a falta de capital pode indicar possíveis ocorrências de erros/fraudes. Já nos red flags não financeiros uma administração desonesta e não ética, segundo Albrecht e Romney (1986), e com a participação constante da entidade em transações consideradas relevantes, pode indicar um ambiente propício para a ocorrência de fraudes, onde a entidade perde a confiabilidade de suas informações apresentadas.

A exemplo das demais empresas, o Banco do Brasil apontou para situações específicas, demonstrando que o controle interno precisa ser alterado e fortalecido. Neste sentido, a utilização do modelo proposto poderá fazer parte do cotidiano da auditoria interna, atuando em tempo na prevenção principalmente de um colapso financeiro na entidade, o que seria significativamente desastroso para todo o Sistema Financeiro 
Nacional, pois além da própria asseguração da entidade em si, ainda existe a regulação deste mercado. Analisando criteriosamente este item, o auditor poderá chegar ao grau de risco assumido nas transações e buscar conclusões sobre eventos subsequentes.

Logo, as análises objetivas e subjetivas resultantes do cruzamento proposto pelo software e que resultou na Figura 1, devem ser feitas pelo auditor, cabendo ao mesmo checar a origem e a fidedignidade da fonte. No caso em tela, foram utilizadas bases de dados secundárias, portanto, as respectivas análises já foram realizadas, cabendo demonstrar a forma como foram realizados os cruzamentos e a sua relação com a fundamentação teórica apresentada.

\section{CONSIDERAÇÓES FINAIS}

Com a combinação dos métodos presentes nesse estudo e apoiado nas teorias apresentadas sobre a utilização dos red flags em bases financeiras e operacionais, foi possível alcançar o objetivo de contribuir com a auditoria, apresentando a construção de um modelo prático, materializado através de um software, cuja aplicabilidade consiste em identificar indícios de erros ou fraudes em demonstrações contábeis e relatórios emitidos.

Ao longo da revisão bibliográfica não foi constatado o cruzamento proposto neste trabalho, originando assim a relação entre causa e efeito proveniente da relação entre red flags financeiros e operacionais. Essa foi a primeira visão extraída e que tornará possível ir além e materializar o modelo em um produto que possa ser útil ao processo de auditoria.

Embora o software esteja em um estado embrionário e em fase de registro, mostrouse de grande valia como forma de percepção complementar ou primária aos trabalhos do auditor independente, tratando-se de um modelo prático e de grande poder de tratamento de dados, função que tomaria muito tempo com leitura e análise preliminar pelos auditores. Logo, em um estágio futuro, espera-se como contribuições que esse software faça parte do cotidiano da auditoria, com uma base de red flags mais ampla, e com métodos quantitativos mais robustos, ampliando o poder de detecção de erros e fraudes.

Para tanto, assim que validado mais amplamente e posteriormente registrado, desejase que o mesmo seja de domínio público e aberto, cabendo então a cada auditor fomentar os red flags que entende como propícios a análise da empresa que irá auditar. Nesse sentido, não foi e não será imputado ao software a incumbência de entender as relações que levaram aos cruzamentos na Figura 1, pois como descrito na fundamentação teórica, tratam-se de sinalizadores e não de evidências em si. 
Este trabalho apresentou como principal limitação a utilização de dados secundários, reduzidos a um número pequeno de empresas públicas. Entretanto, poderá ser minimizada à medida que novos pesquisadores se propuserem a utilizar a lógica do cruzamento aqui proposto, evidenciando a eficiência prática através de outros setores econômicos. Poderá ainda ser acoplado aos resultados futuros uma análise do comportamento e atitudes de gestores, buscando a criação de inibidores como fator de prevenção para as causas de ocorrência de erros e fraudes dentro das entidades.

\section{REFERENCIAS}

ALBRECHT, S.; ROMNEY, M. Red-flagging management fraud: a validation. Advances in Accounting, 3, 323-333, 1986.

ALBRECHT, S. Fraud Examination. São Paulo: Editora Thomson, 2003.

ASSOCIATION OF CERTIFIED FRAUD EXAMINERS. ACFE. - Educação formação e certificação fraude. 2016. Disponível em: <http://www.acfe.com/default.aspx>. Acesso em: 22 set. 2016.

APPOLINÁRIO, F. Dicionário de metodologia científica. São Paulo: Atlas, 2011.

BARDIN, L. Análise de Conteúdo. Lisboa: Edições 70, 1991.

BELL, T.; CARCACELLO, J. A decision aid for accessing the likehood of fraudulent financial reporting. Auditing: A Journal of Practice \& Theory, v. 19, n. 1, 2000.

CRESSEY, D. R. Other people's money: a study in the social psychology of embezzlement. American Sociological Review, v. 16, n. 3, 1954.

CRONBACH, J. L. Coefficient alpha and the internal structure of tests. Psychometrika, v. 16. N. 3, p. 297-334, Set. 1951.

CRONBACH, J. L. My current t procedures. Educational and Psychological Measurement, v. 64, n. 3, Jun. 2004.

EINING, M.; JONES, D.; LOEBBECKE, J. Reliance on decision aids: an examination of auditor's assessment of management fraud. Auditing: A Journal of Practice \& Theory, v. 16, n. 2, p. 1-19, 1997.

ESTEVES, I. I. S. A Responsabilidade social do auditor perante a fraude. $184 \mathrm{f}$.

(Dissertação). Instituto Superior de Contabilidade e Administração de Lisboa. Lisboa-PT, 2012.

GIL, A. C. Como elaborar projetos de pesquisa. 6. ed. São Paulo: Atlas, 2017.

INSTITUTO DOS AUDITORES INDEPENDENTES DO BRASIL -

IBRACON. (2016). Disponível em:

<http://www.ibracon.com.br/ibracon/Portugues/detlnstitucional.php?cod=1>.Acesso em: 05 set. 2016. 
KRANACHER, M.; RILEY, R.; WELLS, J. T. Forensic Accounting and Fraud Examination. Saint Louis: John Wiley, 2010.

MOURA, H. S.; SILVA, A. C. R. Auditoria de fraude: instrumentos na prevenção de fraudes contra as empresas. Anais... X Congresso de Contabilidade - Relato Financeiro e Responsabilidade Social. Centro de Congressos do Estoril, Lisboa, Portugal, 2004.

MOURA, D. Análise dos fatores de convencimento do juízo brasileiro quanto à ocorrência de fraude contábil: um estudo de caso múltiplo da Gallus, da Encol e do Banco Santos. 103 f. (Dissertação). Mestrado Internacional (MIM), Fundação Getúlio Vargas, Rio de Janeiro, Brasil, 2007.

MINISTÉRIO PÚBLICO FEDERAL - MPF (2017). Disponível em:

<http://lavajato.mpf.mp.br/entenda-o-caso>. Acesso em: 20 maio 2017.

MURCIA, F. D.; BORBA, J. A. Estrutura para detecção do risco de fraude nas demonstrações contábeis: mapeando o ambiente fraudulento. Brazilian Business Review, v. 12, n. 3, p. 171-190, 2007.

MURCIA, F. D.; BORBA, J. A.; SCHIEHLL, E. Relevância dos red flags na avaliação do risco de fraudes nas demonstrações contábeis: a percepção dos auditores independentes brasileiros. Universo Contábil, v. 17, p. 25-45, 2008.

PURWANTI, I. G. A. P. D. S.; ASTIKA, I. B. P. Pengaruh Auditor's Professional Skepticism, Red Flags, Beban Kerja Pada Kemampuan Auditor dalam Mendeteksi Fraud. E-Jurnal Akuntansi, v. 21, n. 2, p.1160-1185, 2017.

RAUPP, F. M.; BEUREN, M. I. Como elaborar trabalhos monográficos em contabilidade. São Paulo: Atlas, 2006.

REINSTEIN, A.; MCMILLAN, J. The Enron debate: more than a perfect storm. Critical Perspectives on Accounting, v. 15, p. 955-9790, 2004.

RICARDINO, A.; CARVALHO, L. N. Breve retrospectiva do desenvolvimento das atividades de auditoria no Brasil. Revista Contabilidade \& Finanças, v. 16, p. 22-34, 2004.

RUSTIARINI, N. W.; NOVITASARI, N. L. G. Persepsi Auditor atas Tingkat Efektivitas Red Flags untuk Mendeteksi Kecurangan. Jurnal Akuntansi Multiparadigma, v. 5, n. 3, p.345354, 2014.

SÁ, A. L.; HOOG, W. A. Z. Corrupção, fraude e contabilidade. Rio de Janeiro: Juruá, 2012.

SOUZA, A. J. Normas internacionais de contabilidade: percepções dos peritos criminais federais sobre os impactos de sua adoção na atividade de perícia oficial realizada em fraudes contábeis no Brasil. Brazilian Business Review, v. 19, n.1, p. 53-72, 2012.

STICKNEY, C.; WEIL, R. Financial accounting: an introduction to concepts, methods and uses. New York. Editora Dryden, 2000.

WELLS, J. Principles of fraud examination. New York. Editora Wiley, 2005. 
DOI: 10.18605/2175-7275/cereus.v12n2p163-177

Revista Cereus

2020 Vol. 12. N.2
DE OLIVEIRA, E.C. CARRARO, N.C. SIQUEIRA, L.C. ALMEIDA, O.A.I. ESTEVES, Y.O

Propositura de Construto para Utilização Prática de Red Flags em Auditoria

WUERGES, A. F. E. Detecção de fraudes contábeis: é possível quantificar os casos nãodescobertos? Universo Contábil, v. 23, p. 25-54, 2010 